\section{References and further reading}

CAldicotr. F. (1994) Supervision registers: the College's response. Psychiatric Bulletin, 18, 385-386.

DEPARTMENT OF HEALTH (1992) Revlew of Health and Social Services for Mentally Disordered Offenders and Others Requirting Stmilar Services. London: HMSO.

- (1994) Report of the Department of Health and Home Office Worktng Group on Psychopathic Disorders. London: HMSO.

RitchIE, J. H., Dick. D. \& LinghnM, R. (1994) The Report of the Inquiry tinto the Care and Treatment of Christopher Clunis. London: HMSO.

SOcinl ANd COmmunity PLannma Research (1993) Factors Influencing the Implementation of the Care Programme Approach London: HMSO.

*ANThoNy McCarThy, Clinical Director, Adult Mental Health Lewisham and Guy's Mental Health Trust, Guy's Hospital, St Thomas Street
London SE1 9RT, DAVID ROY, Director of Mental Health, West Lambeth Community Care Trust. South Western Hospital, Pulross Road, Stockwell, London SW9 8EA; FRANK Holloway, Clinical Director, Community Directorate, Maudsley and Bethlem NHS Trust, Denmark Hill, London SE5 8AZ; ZERRIN ATAKan, Consultant Psychiatrist, West Lambeth Community Care Trust, South Western Hospital, Pulross Road, Stockwell, London SW9 8EA; and TONY Goss, Contract Manager, Mental Health and Substance Misuse, Lambeth Southwark and Lewisham Health Commission. 1 Lower Marsh, London SE1

"Correspondence

\title{
To be or not to be discharged: an ethical dilemma
}

\author{
Anita Kotak, Faiz Noore, Kamal Muthiah, Faroogh Raffique \\ and Ulrike Schmidt
}

We describe the problems encountered in deciling with a 'dischorge refuser' in the context of recent government guidalines on good practice in the discherge of mentally disordored people.

A recent Department of Health document on good practice in the discharge of mentally disordered people gives the following guidelines:

"- that psychiatric patients are discharged only when and if they are ready to leave hospital;

- that any risk to the public or to patients themselves is minimal and is managed effectively;

- that when patients are discharged they get the support and supervision they need from the responsible agents." (Department of Health, 1994).
These guidelines written in the wake of the Clunis enquiry and the Silcott affair make sense for dealing with the majority of patients with severe mental illness, in particular those who are reluctant to stay in touch with services and who all too easily slip through the net. These guidelines, however, are not at all helpful in dealing with 'discharge refusers' or 'professional patients'. Azuonye (1989) pointed out that patients have many reasons for refusing discharge including delusional beliefs about their 'rightful' place of residence, reluctance to have yet another move, satisfaction with the 'hotel aspects' of the hospital or the belief that they are 'too ill' to cope in the community. Discharge can be refused through a number of ingenious ways including acting-out or expressing psychoticlike symptoms. Provider units have been 
drtven to drastic action including calling in the hospital porters, security staff or the police to remove the patient off the premises or by threatening discharge refusers with transfer to a long-stay ward. The problems and dilemmas which arose in one such a case are described below.

\section{Case}

Paul is a 30-year-old man with a history of paranoid schizophrenia who was admitted informally to our general psychiatric unit from a hostel for the homeless. Although the admitting hostel was a short-stay hostel he had managed to stay there for 14 months. He was referred to us because there had been an exacerbation of his psychotic symptoms when transfer to a specialised rehabilitation hostel was being arranged.

Paul has had many psychiatric admissions since age 16. In addition to the main diagnosis of paranoid schizophrenia, he has also attracted the diagnosis of sociopathic personality disorder based on a long-standing pattern of disruptive, violent or self-injurious behaviour, such as smashing up his room, setting hospital files alight or attempting to set himself and a hostel on fire. Paul also abuses alcohol and cannabis on a regular basis.

Paul has practically no support from his family. His mother, brother and father all suffer from schizophrenia and his father has also had treatment for alcohol-related problems. Paul is of limited intelligence. He has had poor education and is barely able to read or write.

Soon after admission to our ward his psychotic symptoms settled without any change in his depot neuroleptic medication and he was - as planned - sent on a trial stay to his new hostel. The first visit went well; however, Paul then refused to return to the hostel. In close liaison with hostel staff he was persuaded to visit the hostel again for a brief stay; however, he sabotaged a permanent placement by setting off the fire alarm in the middle of the night and barricading himself in his room and when confronted with this he threw a chair at a member of hostel stafi.

A second attempt to discharge him to a different hostel also failed. He initially agreed to this plan but prior to any visits his aggresstve behaviour on the ward would escalate and he would find a number of excuses as to why he could not visit the hostel. Examples included people staring at him on the tube or running out of money. When asked to account for his behaviour he agreed that he would prefer to stay in hospital permanently, as he felt safe there. A third hostel placement was secured, but fell through at the last minute, when it was discovered that this hostel was under investigation for unsatisfactory practices.

Paul has now been on our ward for nearly a year. His psychosis has been well-controlled throughout this time on a moderately high dose of a depot neuroleptic. His behaviour fluctuates. At times he can be rather child-like, friendly and compliant. At other times, he can be verbally abustve and threatening, kicking doors and on one occasion he has attacked a nurse, attempting to strangle him. These incidents tend to happen either when he is intoxicated or when staff are busy with other patients and he feels he is not given enough attention. Because we were concerned that Paul was getting a lot of negattve attention reinforcing his problematic behaviour, we instituted a behavioural programme in an effort to maximise positive attention when he behaved appropriately and to ignore negative behaviour as much as possible. However, this programme falled for a mixture of reasons including staff shortages. Paul has also had the benefit of two 'second opinions' from other consultant psychiatrists with particular expertise in forensic psychiatry and personality problems, who essentially sympathised with the difficulties in looking after Paul.

\section{Dilemma}

We see Paul as someone who is certainly vulnerable and who is going to require longterm care and supervision. A past history of 14 months of adequate functioning in a hostel suggests that he can survive in a wellsupervised hostel with qualified staff in the community. However, at present to persevere with further attempts to rehabilitate him and move him to the community seems a futlle exercise, as he is so clearly sabotaging our efforts to do so. Paul is currently a patient in a busy acute psychiatric admission ward in an inner London hospital with a high turnover of patients and great pressure on beds. In this setting Paul's repeated acting-out has a very negative effect on fellow-patients and staff as well as him. 
Taking these factors into account we have identified two potential diametrically opposed therapeutic options that could be pursued with Paul.

\section{Option 1}

It could be argued that because Paul is sabotaging his discharge deliberately he should be put on a contract specifying that in the case of unacceptable behaviour on the ward he would be discharged from hospital to bed and breakfast accommodation with community support and with the aim to work towards a hostel placement from there.

\section{Option 2}

Given that his behaviour can at times be frightening and puts Paul and others at considerable risk an alternative option would be to detain Paul under section 3 of the Mental Health Act (1983), in the category of 'psychopathic disorder', nurse him in the intenstve care unit of the hospital and aim to transfer him to a unit specialising in patients with challenging behaviours as soon as a bed becomes available.

Both these options have some advantages but also considerable disadvantages attached to them.

\section{Option 1}

\section{Advantages}

(a) This option treats Paul as an individual who has responsibility for his actions and has to live with their consequences. It might help him understand that he is not just a passive recipient of care but that he is directly involved in his care and has an effect on the care he is given.

\section{Disaduantages}

(a) Paul has become very adept at using high-risk strategies for sabotaging his discharge. He is not very articulate and often unable to express his feelings in any other way than through actions. If he were to be discharged following a breach of his contract, it is possible that in an attempt to force his way back into hospital he would use dangerous means for readmission (including suicide attempts or fire-setting).

(b) This option could be perceived as being in breach of recent government guidelines. Should Paul or someone else come to harm if he had to be discharged, this could easily be construed as another example of community care having gone wrong.

\section{Option 2}

\section{Advantages}

(a) In the current political climate this is the safest option for the professionals working with Paul as it involves the passing on of responsibility to other professionals.

(b) This option does offer containment to Paul and may - if successful - in the long run help to break his cycle of maladaptive behaviours.

\section{Disaduantages}

(a) Being in hospital in many ways fuels his disturbed behaviour. In an environment catering for the needs of highly disturbed patients (e.g. challenging behaviours unit) he is likely to increase his repertoire of maladaptive behaviours. This may mean that he will 'up the stakes' to get attention by harming himself or others. He may thereby increase the levels of restriction needed.

(b) Given his limited intelligence and suggestibility there is a considerable potential for him being abused and exploited by other patients. For example, on our ward he got very involved with a very intelligent, but disturbed HIV-positive patient and there were serious concerns that Paul might have a sexual relationship with this man, who provided him with alcohol and drugs.

(c) This option robs him of his freedom to come and go which he very much enjoys and on many occasions uses appropriately.

\section{Conclusions}

The depressing conclusion drawn by Azuonye in 1989 about discharge refusers is as follows: "It is when patients who are percetved as vulnerable are concerned that it (the 
situation) becomes somewhat more complex. In my experience, discharge refusers of this kind generally get their way, they are allowed to stay on in hospital, the situation to be reviewed at a later date. The act of refusal of discharge may even prompt a reappraisal of the patient's mental condition, as doubt is then cast on the patient's initial readiness for discharge."

An alternattve view is that the dilemma presented in this article is based on a false dichotomy. In calling Paul a 'discharge' refuser the underlying assumption is - in line with our current community-oriented philosophy of health care-delivery - that more or less all patients have to be rehabilitated to the community, at some stage or other. Until a few years ago a third option for someone like Paul might have been to find sanctuary in a long-stay ward. This option no longer exists (Coid, 1994).

Within the confines of existing options we feel that recent government guidelines have added a new layer of complexity to the dilemma as to whether or not to discharge patients like Paul. What previously might have been thought of as an acceptable therapeutic risk when working with patients like him, may now be construed as a lack of adequate care and supervision. We cannot help feeling that this amounts to practising defensive medicine. Consultant psychiatrists are now taking fewer risks, and this has important knock-on effects on bed availability in psychiatric units (Foster, 1994). A corollary of this is that junior doctors assessing patients in casualty have to raise their threshold for admitting people into hospitals. Thus the responsibility for risky decisions gets shifted from consultant psychiatrists to junior doctors in casualty (Foster, 1994).

\section{References}

Azuonye, I. O. (1989). Discharge refusers. Psychiatric Bullettr, 13. 199-200.

Com J. (1994). The Christopher Clunis enquiry. Psychiatic Bulletin, 18, 449-452.

DEPARTMENT OF HEALTH (1994). Guldance on the Discharge of Mentally Disondered People and thetr Conttinuting Care in the Communtty. NHS Executtve HSG (94) 27.

FOSTER, F. (1994) Shortage of beds. Psychiatric Bullettn, 18. 371-372.

ANITA KoTAK, Registrar in Psychiatry: FAlz NOORE, Senior Registrar in Psychiatry; KAMAL Mutriah, Clinical Research Fellow; FArOOQH RAFFigU, GP trainee; and ULRIKE SCHMIDT, Consultant Psychiatrist, Department of Psychiatry, St. Mary's Hospital, Paterson Wing, Praed Street, London W2 INY 